\title{
Can a new classification of coquinas show better relationships with acoustic velocities?
}

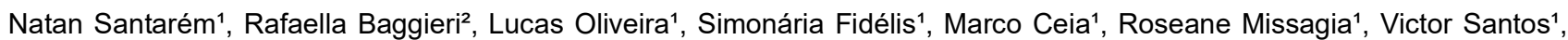
Entities ${ }^{1}$ - UENF/LENEP/MIR, ${ }^{2}$ - FACC

Copyright 2021, SBGf - Sociedade Brasileira de Geofísica

This paper was prepared for presentation during the $17^{\text {th }}$ International Congress of the Brazilian Geophysical Society held in Rio de Janeiro, Brazil, 16-19 August 2021.

Contents of this paper were reviewed by the Technical Committee of the $17^{\text {th }}$ International Congress of the Brazilian Geophysical Society and do not necessarily represent any position of the SBGf, its officers or members. Electronic reproduction or storage of any part of this paper for commercial purposes without the written consent of the Brazilian Geophysical Society is prohibited.

\begin{abstract}
Reservoir characterization has often utilized correlations between lithology and acoustic velocities. Due to giant oil discoveries at pre-salt carbonate rocks, a large effort was made to understand all the geological aspects related to these rocks, and at this point, Morro do Chaves coquinas has emerged as an essential analog with the Aptian bioclastic deposit at Campos and Santos Basin. Those rocks were analyzed in a series of studies, although few publications were made in association with acoustic properties. Coquinas have been described by the traditional classification of carbonates, but due to the intense diagenesis of the shells and the significant content of siliciclastic material, a new classification of carbonates has emerged. Due to the complexity of carbonate rocks, the application of a detailed description of coquina deposits was a critical aspect of velocity interpretation. This work aims to evaluate the correlations between acoustic properties and both carbonate classifications (the classic and the new one). Compared to the traditional classification, the new carbonate classification for the coquinas of the Morro do Chaves Formation showed a modest increase in the correlations of compressional wave velocities with other rock properties. Acoustic velocities were influenced more by pore type than mineralogy or total porosity.
\end{abstract}

\section{Introduction}

Understanding carbonate rocks only from a geological point of view sometimes can be a huge challenge by itself. The geological description at reservoir characterization, despite being particularly important, still needs to communicate with other areas to formulate interpretive models to be applied at exploration and development.

Acoustic velocities have been used to improve reservoir evaluation. The study of the physical properties of rocks is important for reservoir characterization and monitoring. Reservoir carbonate rocks might have a complex pore structure, depositional texture, and mineralogical composition, resulting in different parameters that directly affect the velocities of seismic waves. Correlations between lithology and acoustic velocities are more evident in sandstones than carbonates (Eberli et al., 2003). Even carbonate rocks are dominated by calcite and sometimes dolomite, they commonly display heterogeneities due to diagenesis and show a variety of complex pore structures and laterally and horizontally texture variations that may cause a velocity deviation (Anselmetti and Eberli, 1993, 1999; Berryman and Blair, 1987; Mavko et al., 2009).

Generally, for the oil industry, carbonate rocks are classified as the propositions of Dunham (1962). This traditional classification was made for detrital carbonates based on the concept of textural maturity applied to terrigenous for carbonates, making it possible to recognize features of selection and factory. The denominations used are an attempt to reflect the energetic environment.

On the other hand, the terms adopted by Dunham (1962) do not classify hybrid coquinas compared to other carbonate rocks, because at certain times, the siliciclastic content is abundant (almost 1:1). Another critical issue is that the classic classification presents little flexibility in the classification of diagenetically altered rocks. Relationships between porosity and velocity in carbonate rocks can be exceedingly difficult to determine when types of cement formed at different diagenetic stages occur (Eberli et al., 2003)

Borghi (2020) proposes a new classification for the bioclastic deposits from Morro do Chaves Formation (Figure 1). The new classification proposes to cover doubtful points to past classifications (presence of siliciclastic) and has different nomenclatures for rocks with a sandy and muddy matrix. The degree of sphericity and packing (dispersed, loose, and dense) together with the matrix/cement quantification is used as modifiers, which provides greater detail for rocks where diagenetic features exist or predominate. 
Can a new classification of coquina show better relationships with acoustic velocities?

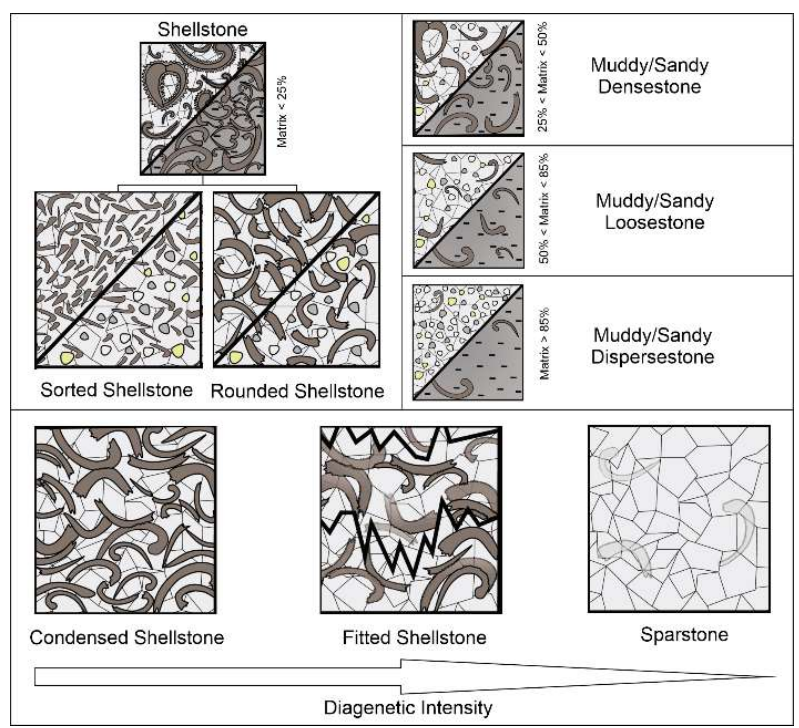

Figure 1: Classification of coquinas based on taphonomic, sedimentological and diagenetic aspects, modified from Borghi (2020).

This study focuses on the relationships between coquinas classification and acoustic properties. For this idea, we studied carbonate rock samples from Morro do Chaves Formation (Sergipe-Alagoas Basin), which have been used as an analog of pre-salt bioclastic deposits (Castro, 2011). Although Morro do Chaves's coquinas are known as carbonate rocks, Tavares et al. (2015) argue that coquinas could be considered hybrid rocks, i.e., not only composed of shells and their fragments, but siliciclastic material is commonly present. Twenty-four samples were classified using Dunham's (1962) and Borghi's (2020) classifications and correlated with acoustic properties at dry conditions. Other parameters of the samples (e.g., porosity, bulk density, mineralogical content, and pore type) were used to support the analysis.

\section{Methodology}

Petrographic analysis and classification of depositional texture

A transmitted light petrographic microscope coupled to an AxioCam HRc camera with AxioVision software was used to the rock classification, evaluate the pore types, and obtain petrographic images. The petrographic thinsections images were analyzed to describe the internal structure of samples, aided by the classic and new textural classification (Figure 2) and the pore classifications of Choquette and Pray (1970).

\section{Wave velocities determination}

The international standard ASTM D2845-08 (2008) was applied to determine the seismic velocity waves ( $\mathrm{P}$ - and $\mathrm{S}$-waves). Therefore, $\mathrm{P}$ - and $\mathrm{S}$-wave velocities were measured under dry and ultrasonic conditions using effective pressure between 5-10 MPa. Based on measured values of $\mathrm{Vp}$ and $\mathrm{Vs}$ together with bulk density $\left(\rho_{\text {bulk }}\right)$, it is usual to estimate the bulk modulus (Kdry), also called incompressibility, and $\mathrm{P}$ acoustic impedance $\left(\mathrm{Al}_{\mathrm{p}}\right)$ for dry condition, as follows (MAVKO; MUKERJI; DVORKIN, 2009):

$$
\begin{aligned}
& K_{d r y}=\rho_{\text {bulk }}\left(V p^{2}-\frac{4}{3} V s^{2}\right) \\
& A I_{p}=\rho_{\text {bulk }} V p
\end{aligned}
$$
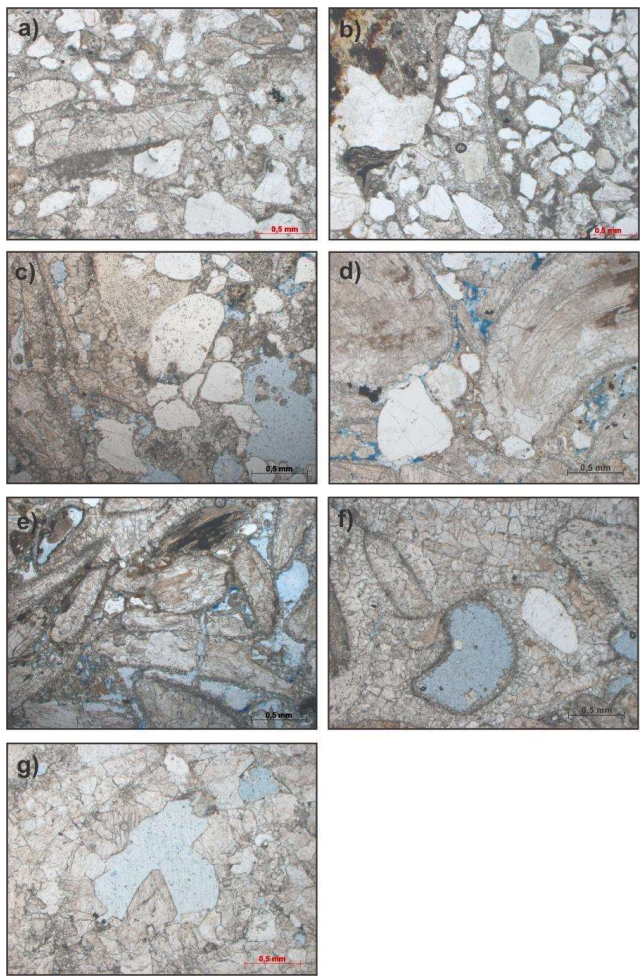

Figure 2: Thin-section photomicrographs of coquinas from Morro do Chaves Fm. by Borghi (2020); a) Sandy Dispersestone (PPL); b) Sandy Loosestone (PPL); c) Sandy Desestone (PPL); d) Sorted Shellstone (PPL); e) Condensed Shellstone (PPL); f) Fitted Shellstone (PPL); g) Sparstone (PPL).

\section{Mineralogy and porosity estimation}

The analysis of the mineral composition of the samples was determined by X-ray diffractometry (XRD). X-ray diffraction analysis to mineral composition quantification is based on the Rietveld method (Rietveld, 1969). This method enables adjusting different XRD patterns and obtains the best fit between the experimental measurement and the fitted equation (Archilla et al., 2016). From the mineral weights in combination with properties describes in the literature, it is possible to calculate mineral bulk modulus with the Voigt-Reuss-Hill average, as following: 
$K_{m V}=\sum_{\substack{i=1 \\ n}}^{n} f_{i} K_{m i}$,

$K_{m R}=\sum_{i=1}^{n} \frac{f_{i}}{K_{m i}}$

$K_{m}=K_{V R H}=\frac{K_{m V}+K_{m R}}{2}$.

Total porosity $(\phi)$, grain, and bulk densities were measured by a helium gas porosimeter (Ultrapore 300). This equipment performs measurements of matrix volume of samples through gas expansion technique and Boyle's Law (Tiab and Donaldson, 2015), allowing to determine the porosity, bulk (Eq. 6), and mineral (grain) densities ( $\rho$ bulk and $K \mathrm{~m}$, respectively).

$\rho_{\text {bulk }}=(1-\phi) \rho_{m}+\phi \rho_{f l}$,

were $\rho_{\mathrm{fl}}$ is the pore fluid density, in this case, air.

\section{Results}

Rock Classification vs. Acoustic Properties

Twenty-four samples were analyzed, using microscopic petrography to describe each sample as proposed by the classifications of Borghi et al. (2020) and Dunham (1962). According to the classic classification, nineteen samples were classified as Rudstones, two as Grainstones, and three as Packstones. The new classification has presented more subdivisions compared to Dunham (1962). Of the total samples, three were identified as Spartones, five as Fitted Shellstones, four as Condensed Shellstone, two as Sorted Shellstone, seven as Sandy Densestone, two as Sandy Loosestone, and a single sample was classified as Sandy Dispersestone (Figure 2).

The mineral occurrence was stipulated for each rock sample from the analysis of XRD concomitantly with the petrographic interpretation. In the data set, it is possible to observe that calcite is the primary mineral occurrence (ranges from $45 \%$ to $99.5 \%$ ), associated with bivalve clasts or as a product of diagenesis (sometimes, both). It is noteworthy that calcite is probably a product of the dissolution of primary aragonite. Silica is the mineral with the second-highest occurrence (ranges from $0.45 \%$ to $45 \%$ ). Other minerals observed are Pyrite, Microcline, Iron oxides as cement, and lithoclasts. The occurrence of Dolomite was not observed in any sample.

Although the coquinas of the Morro do Chaves Formation are considered carbonate rocks, there is the occurrence of associated siliciclastic minerals. The variation in the calcite content at these rocks and the occurrence of other siliciclastic minerals can impact the acoustic measurements considering that different minerals present different densities and elastic modulus.

In carbonate rocks, it is known that a diversity of factors can modify the primary depositional conditions and that, consequently, they impact the interpretations and correlations with the acoustic velocities. Dunham's (1962) classification does not focus on describing diagenetic characteristics, which can be problematic when correlating geological aspects with petrophysics and elastic waves. The traditional classification by itself does not give many answers. The only logical correlation observed is that in rocks with larger grains and with better textural selection (expected with grainstones and rudstones) we would presume more primary pore space, leading to little $P$ and $S$ velocities. In addition to focusing on the concentration of bioclasts and the relative proportion of associated terrigenous, Borghi's (2020) classification also considers diagenetic characteristics to establish a classification more compatible with the geological history in which the rock suffered (Figure 1).

a)

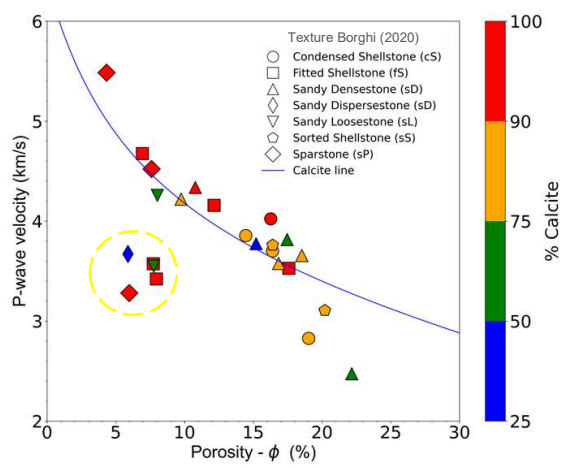

b)

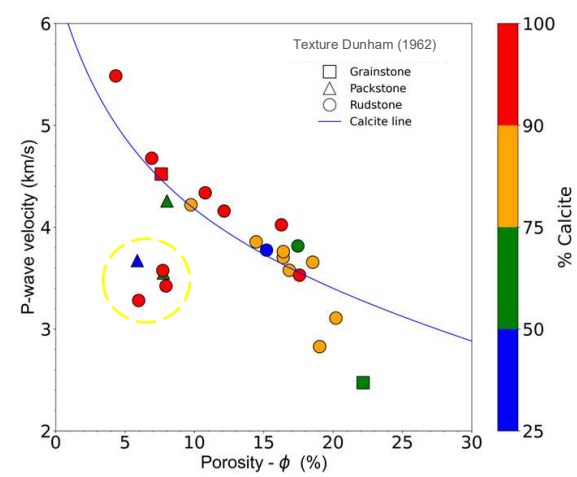

Figure 3: a) Vp-porosity-calcite correlations by Borghi (2020); b) Vp-porosity-calcite correlations by Dunham (1962). The symbols indicate porosity type. Yellow circle indicates anomalous samples and the solid line represents the time-average equation for calcite (Wyllie et al., 1956).

The measured velocities can be compared with a predicted line proposed by Wyllie et al. (1956) (Figure 3a and $3 \mathrm{~b}$ ). The samples of coquina with more than $90 \%$ calcite (pure limestones) present porosities between 5 and $18.5 \%$ and $V p$ between 3 and $5.5 \mathrm{~km} / \mathrm{s}$. Samples with calcite content between 90 and $50 \%$ (impure limestones) have porosities between 7.5 and $22.5 \%$ and $\mathrm{Vp}$ velocities between 2.5 and $4.3 \mathrm{~km} / \mathrm{s}$. Samples with less than $50 \%$ calcite have porosities between 5 and $15 \%$ and velocities around $3.8 \mathrm{~km} / \mathrm{s}$. From $\mathrm{Vp}$ and texture correlations, it is observed that Dunham's (1962) classification concentrates a large part of the rocks in a single lithotype, making it difficult to identify any pattern or correlation with 
Vp. It is possible to observe that Rudstone samples dominate the data set, with quite different $V p$ values from each other in the same porosity values, making difficult a correlation between possible geological processes and their associated responses and propagation of Vp (Figure 3).

The dataset differentiates itself more clearly from Borghi's (2020) classification since the authors subdivide their classification in different concentrations of terrigenous and bioclastic content. Among the lithotypes proposed by this new classification, it is noted that the samples with less porosity are Sparstones which was expected due to intense obliteration of the pore space by diagenetic cementation. The most cemented samples (Sparstone and Fitted Shellstone), which underwent high diagenetic intensity, are those that have the most considerable calcite content in the form of cement, and therefore, the highest velocities. Samples showing low porosity values (low primary porosity or high cementation), in theory, should have the highest $\mathrm{Vp}$ value in proportion to porosity. Even so, this lithotype (carbonate with high sparite concentration and less than $25 \%$ of terrigenous content) presents different values for $V p$ at the same porosity range.

Despite separating the data set more coherently concerning mineralogy, the new classification is still not able to clearly explain some points where there are ranges between $3 \mathrm{~km} / \mathrm{s}$ to $6 \mathrm{~km} / \mathrm{s}$ at the same porosity value and with the same mineralogical content and at the same lithotype. However, at Borghi's (2020) classification, those "outliers" are more noticeable than Dunham's (1962) classification, mainly because it is easier to determine if those samples have the same mineralogical content at the same porosity range.

However, due to the different types of porosity observed in these samples and the mineralogy content, the wide range of $\mathrm{Vp}$ values in the data set must be explained by differences in the pore type and possible correlations with mineralogy.

\section{Porosity types with mineralogy}

From the petrography analysis, five pore types were recognized. Vuggy porosity is the significant occurrence at the coquinas analyzed (twelve samples). Interparticle porosity was observed in five samples. One sample was classified as Intracrystalline porosity and one as Moldic. From the twenty-four samples, we are unable to identify any dominant pore type at petrographic description. At the helium gas porosimeter routines, were possible to identify porosity at those five samples, none of them with more than $8 \%$ porosity. For those samples, we assume the occurrence of micropores, which were impossible to see at thin sections.

There is an inverse porosity-velocity correlation; velocity decreases with increasing porosity from the microporosity to vuggy. However, some samples are not affected by the total porosity, because there is a spread of velocity (around $3.4 \mathrm{~km} / \mathrm{s}$ to $4.5 \mathrm{~km} / \mathrm{s}$ ) at $8 \%$ porosity (Figure 4 ).
Most samples have more than one pore type, which may explain some velocity scattering in the same porosity, such as the anomalous samples (yellow circle) that in the same porosity, dominant pore type, and mineralogy show lower velocities. The pore geometry could explain that velocity scattering as well.

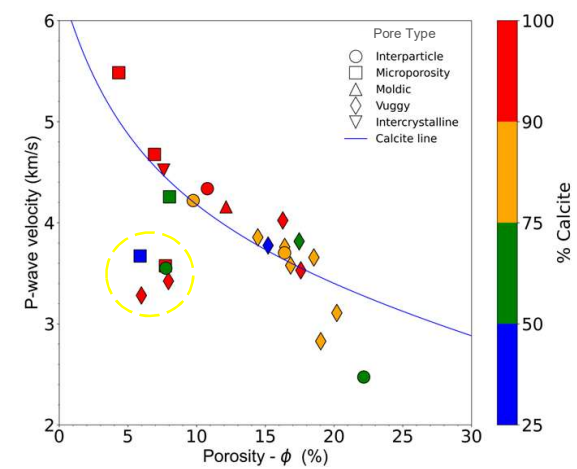

Figure 4: Vp-porosity-calcite correlations for pore type. The symbols indicate porosity type. Yellow circle indicates anomalous samples and the solid line represents the time-average equation for calcite (Wyllie et al., 1956).

\section{Acoustic Impedance and Incompressibility}

To better understand the impact of mineralogy and porosity with $\mathrm{Vp}$ values and their relationships between the author's classifications, Kdry/Km ratio (Figures 5 and $6)$, and acoustic impedance $\left(A I_{p}\right)$ was calculated as shown in equations 1,2 , and 5 , respectively. Correlations between the $\mathrm{Kdry} / \mathrm{Km}$ ratio with porosity and $\mathrm{Vp}$ were made.

a)

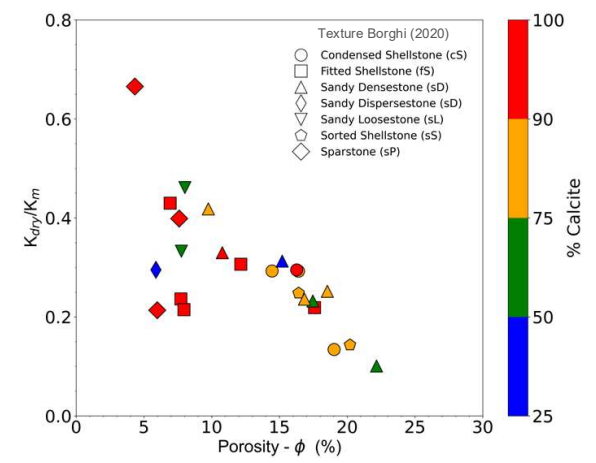

b)

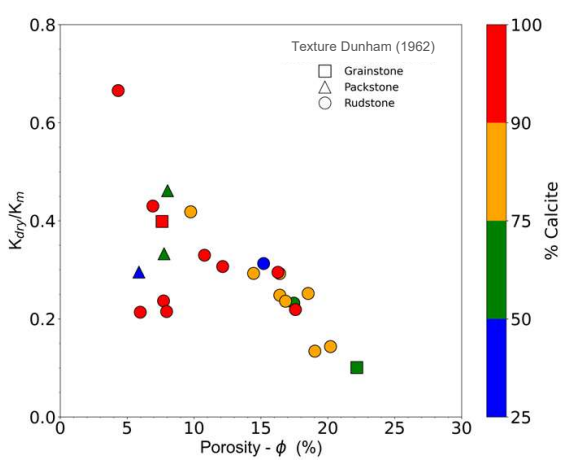


c)

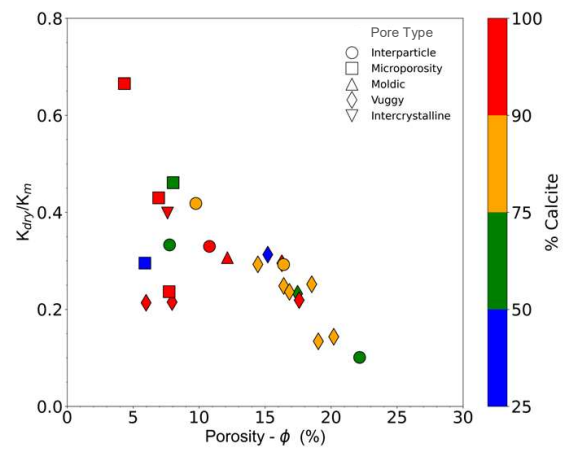

Figure 5: Crossplots of Kdry/Km vs. porosity for coquinas from Morro do Chaves Formation; a) crossplot by Borghi (2020); b) crossplot by Dunham (1962); c) crossplot for pore types.

None of the rock classifications shows a better correlation with the $\mathrm{Kdry} / \mathrm{Km}$ ratio. $\mathrm{Kdry} / \mathrm{Km}$ vs. porosity plots demonstrate that in fact (Figure $5 a$ and $5 b$ ), the higher the porosity, the lower the ratio, and consequently the lower the Kdry (Figure 5c). It is noticed that the samples with the highest relative $\mathrm{Kdry} / \mathrm{Km}$ values at the top are those that have less porosity, so a greater contribution of grains in the incompressibility value of the dry rock, associated with a contribution of the tighten pores. They are essentially composed of calcite, with higher and with microporosity and intercrystalline porosity (Figure $5 \mathrm{c}$ ). The amount of pore space more impacts all samples showing the lowest relative values of $\mathrm{Kdry} / \mathrm{Km}$ (below 0.3 ) than grains (mineralogical content).

a)

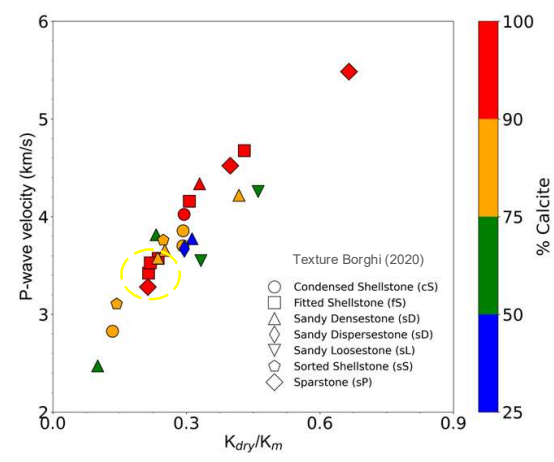

b)

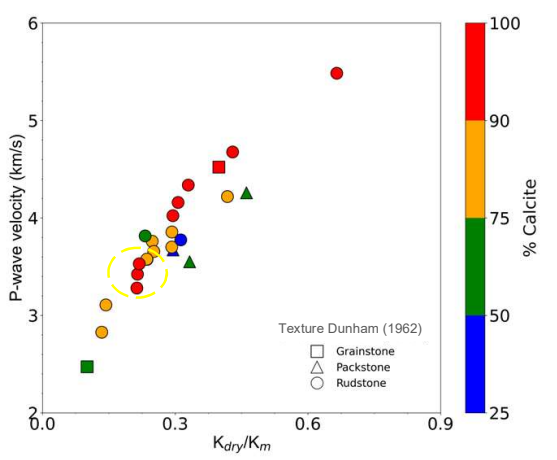

c)

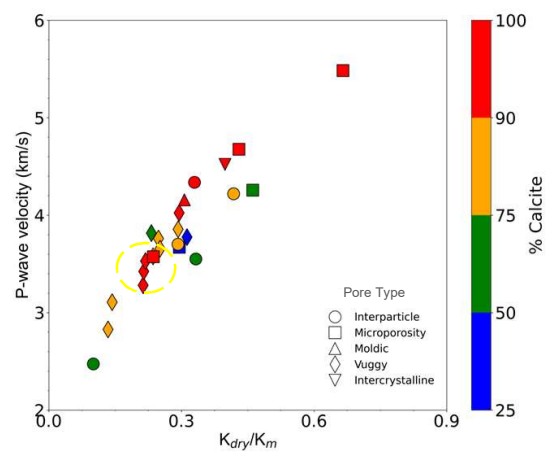

Figure 6: Crossplots of $\mathrm{Vp}$ vs. Kdry/Km for coquinas from Morro do Chaves Formation; a) crossplot by Borghi (2020); b) crossplot by Dunham (1962); c) crossplot for pore types. The dashed yellow circle highlights the samples with calcite content above $90 \%$ at these low Vp and $\mathrm{Kdry} / \mathrm{Km}$ values.

At $\mathrm{Kdry} / \mathrm{Km}$ vs. $\mathrm{Vp}$, a linear trend is observed as expected but at the same porosity ranges, the $\mathrm{Kdry} / \mathrm{Km}$ ratio values are influenced by the pore types (Figure 6 ). It is possible to recognize that Vug pores are associated with lower Kdry values and tend to attenuate $V p$ velocities and impact anisotropy. As the Kdry decreases, we should observe a reduction in $\mathrm{Vp}$ values. As $\mathrm{Vp}$ and $\mathrm{Kdry} / \mathrm{Km}$ crossplot, as $\mathrm{Vp}$ increases (velocities between 4 and 5.5 $\mathrm{km} / \mathrm{s}$ ), the $\mathrm{K}$ (dry and mineral) tends to be higher. We have higher $P$ values for more closed pore types (micro and intercrystalline porosity) and higher calcite contents in ranges of values of equal $\mathrm{K}$ ratio. Samples with less than $90 \%$ of calcite content and velocities below $4 \mathrm{~km} / \mathrm{s}$ are dominated by vuggy porosity, with only three samples with calcite content above $90 \%$ (dashed black circle) at this range (Figure 6c). Those three samples are another indication of the impact of pore geometry and vug porosity at $\mathrm{Vp}$ estimation. As noticed before, pore types are more prone to impact velocity measures at this data if in comparison with mineralogy content, which we can see at high calcite contents $(>90 \%)$, where we have ranges from 0.3 to 0.6 for $\mathrm{Kdry} / \mathrm{Km}$ and $3.5 \mathrm{~km} / \mathrm{s}$ to $5.5 \mathrm{~km} / \mathrm{s}$ for $\mathrm{Vp}$ and different pore types.

The impedance-porosity-density correlation shows a trend of decreasing impedance with decreasing density and increasing porosity (Figures $7 \mathrm{a}$ and $7 \mathrm{~b}$ ).

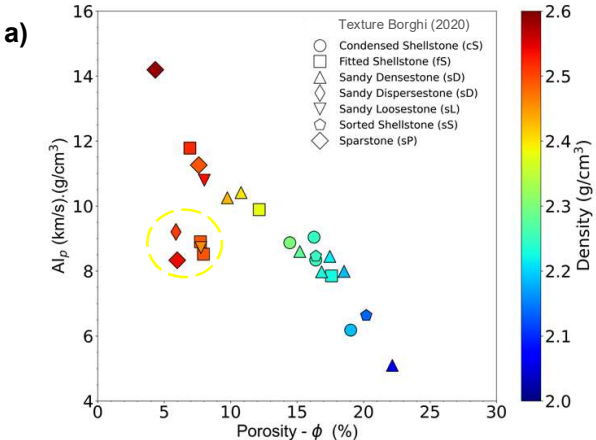


Can a new classification of coquina show better relationships with acoustic velocities?

b)

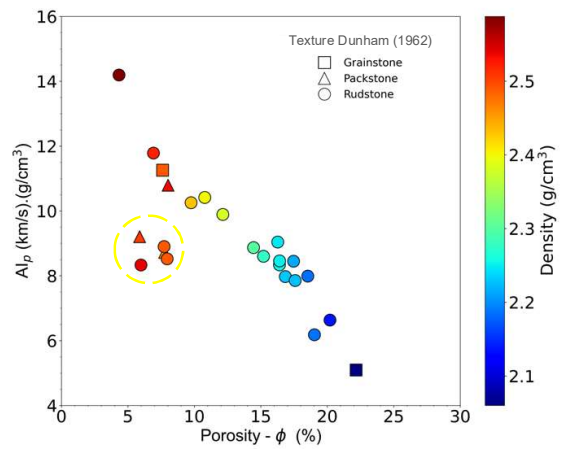

Figure 7: Crossplots of acoustic impedance vs. porosity; a) crossplot by Borghi (2020); b) crossplot by Dunham (1962). The yellow dashed circle highlights anomalous samples.

In regions with similar values of $A l_{p}, \mathrm{Vp}$, and density, there is a discrepancy in the concentration of calcite. The rocks with vug pores possibly present more significant attenuation in the $V p$ as compared to samples with microporosity, impacting the acoustic impedance and $\mathrm{Vp}$ values.

The most cemented samples by Borghi (2020) classification, such as, Sparstone and Fitted Shellstone show the highest acoustic impedances and bulk densities, except for the five anomalous samples (yellow circle) that have specific characteristics. The blue color samples have the lowest bulk densities and acoustic impedances and are related with well sorted and with good maturity rocks (Condensed Shellstone, Sandy Densestone, and Sorted Shellstone), which are expected to have better primary porosity. It seems easier to understand the relationships between porosity and acoustic impedance as we interpreted the data with the new classification. We have the modifiers that indicate an increase in cement and/or diagenetic features that act to minimize the primary porosity. At Dunham's (1962) classification, we cannot deduce those aspects.

\section{Conclusions}

The carbonate classification of Borghi (2020) for the coquinas of Morro do Chaves Formation showed a slight improvement in the correlations of the compressional wave velocities with other properties compared to Dunham's (1962) classification. The pore type had a more notable impact on acoustic velocities than mineralogy and total porosity. Some samples showed anomalous velocity behaviors. The existence of minor pore types, in addition to the pore structure, may explain these anomalous behaviors. Studies on the pore geometry and a more extensive data set, may emphasize an improvement in the interpretation of velocities through this new classification of bioclastic rocks.

\section{Acknowledgments}

This study was financed in part by the Coordenação de Aperfeiçoamento de Pessoal de Nível Superior - Brazil (CAPES) - Finance Code 001 and Petrobras (Process 2017/00067-9). MC and RM thank INCT/Geofisica for financial support, and CNPq for their Research Grants of Productivity in Technological Development and Innovation - DT II.

\section{References}

Anselmetti, F.S., Eberli, G.P., 1999. The VelocityDeviation Log: A Tool to Predict Pore Type and Permeability Trends in Carbonate Drill Holes from Sonic and Porosity or Density Logs. Am. Assoc. Pet. Geol. Bull. 83 (1999). https://doi.org/10.1306/00AA9BCE-173011D7-8645000102C1865D

Anselmetti, F.S., Eberli, G.P., 1993. Controls on sonic velocity in carbonates. Pure Appl. Geophys. PAGEOPH 141, 287-323. https://doi.org/10.1007/BF00998333

Berryman, J.G., Blair, S.C., 1987. Kozeny-Carman relations and image processing methods for estimating Darcy's constant. J. Appl. Phys. 62, 2221-2228. https://doi.org/10.1063/1.339497

Choquette, P.W., Pray, L.C., 1970. Geologic Nomenclature and Classification of Porosity in Sedimentary Carbonates. Am. Assoc. Pet. Geol. Bull. 54. https://doi.org/10.1306/5D25C98B-16C1-11D78645000102C1865D

Borghi - Classificação, in Dal'Bó, P.F., Valle, B., Favoreto, J., Mendes, M., Rigueti, A.L., Borghi, L., PortoBarros, J. P., 2020. Coquinas da Formação Morro do Chaves: Tafonomia, Diagênese, Porosidade e Classificação, 1st ed. Albatroz, Rio de Janeiro, Brasil.

Dunham, R.J., 1962. Classification of Carbonate Rocks According to Depositional Textures 38, 108-121.

Eberli, G.P., Baechle, G.T., Anselmetti, F.S., Incze, M.L., 2003. Factors controlling elastic properties in carbonate sediments and rocks. Lead. Edge 22, 654-660. https://doi.org/10.1190/1.1599691

Mavko, G., Mukerji, T., Dvorkin, J., 2009. The rock physics handbook: Tools for seismic analysis of porous media. Cambridge university press.

TAVARES, A.C., BORGHI, L., CORBETT, P. Facies and depositional environments for the coquinas of the Morro do Chaves Formation, Sergipe-Alagoas Basin, defined by taphonomic and compositional criteria. Brazilian Journal of Geology, [S. I.], v. 45, n. 3, p. 415-429, 2015. Available at: https://doi.org/10.1590/2317-488920150030211

TREIBER, L. E.; ARCHER, D, L.; OWENS, W, W. A Laboratory Evaluation of the Wettability of Fifty OilProducing Reservoirs. In SPE Annual Fall Meeting, Oct/26,1972 , New Orleans. Conference. American Institute of Mining, Metallurgical and Petroleum Engineers. 